\title{
Identification of mandibular fracture epidemiology in Canada: Enhancing injury prevention and patient evaluation
}

\author{
M Czerwinski MD¹, WL Parker MD PhD FRCSC FACS ${ }^{2}$, A Chehade BSc DDS MSc ${ }^{3}$, HB Williams MD FRCSC FACS ${ }^{4}$
}

\begin{abstract}
M Czerwinski, WL Parker, A Chehade, HB Williams. Identification of mandibular fracture epidemiology in Canada: Enhancing injury prevention and patient evaluation. Can J Plast Surg 2008;16(1):36-40.
\end{abstract}

BACKGROUND: Mandibular fractures can lead to significant functional and aesthetic sequelae if treated improperly. They may act as an indicator of concomitant trauma and are very demanding on the public health care system. Thus, knowledge of mandibular fracture epidemiology is critical to effective prevention, as well the establishment of accurate trauma evaluation protocols.

OBJECTIVES: To identify the epidemiology of mandibular fractures treated at a level 1 Canadian trauma centre, clarify the pathogenesis of these epidemiological patterns and suggest potential targets for preventive efforts

METHODS: A retrospective review of all mandibular fracture patients presenting to the Montreal General Hospital between 1998 and 2003 was performed. Medical records and digitized radiographic imaging were used to collect patient demographics and injury data. RESULTS: The chart review identified 181 patients with 307 mandibular fractures. Fifty-two per cent of the fractures occurred in individuals 21 to 40 years of age, $78 \%$ of patients were male, and there was wide ethnic diversity. Sixty percent of patients had multiple mandibular fractures; $29 \%$ were symphyseal/parasymphyseal fractures, $25 \%$ were condylar fractures and $23 \%$ were angle fractures. Assault was the most common mechanism of injury, with $29 \%$ of fractures involving alcohol or illegal drug use. Thirty percent of patients had an associated facial fracture, and more than one-third had another major injury.

CONCLUSIONS: The present epidemiological review reveals several potential prevention targets as well as significant trends. Further research into the impact of these preventive measures could more objectively identify their impact on mandibular trauma.

Key Words: Epidemiology; Facial trauma; Mandible fracture; Prevention

$\mathrm{D}$ ue to the mandible's prominent and unprotected location, it is susceptible to a variety of traumatic insults, making it the second most frequently fractured adult facial bone (1-3). Importantly, mandibular fractures can lead to significant functional and aesthetic sequelae if treated incorrectly, including facial asymmetry, malocclusion, temporomandibular joint disorders and osteomyelitis. In
Épidémiologie des fractures de la mandibule au Canada : amélioration de la prévention de ce type de blessure et de l'évaluation des patients

CONTEXTE : Les fractures de la mandibule peuvent conduire à des séquelles importantes sur les plans fonctionnel et esthétique si elles ne sont pas bien traitées. Elles peuvent être l'indication d'un trauma concomitant et elles sont très coûteuses pour le système de santé public. Aussi importe-t-il de mieux connaître l'épidémiologie des fractures de la mandibule afin de concevoir des moyens efficaces de prévention et d'établir des protocoles d'évaluation précise des traumas.

BUTS : L'étude avait pour buts de dégager l'épidémiologie des fractures de la mandibule traitées dans un centre de traumatologie de niveau I, au Canada; de clarifier la pathogenèse des tendances épidémiologiques et de tenter de déterminer des cibles possibles de prévention.

MÉTHODE : Nous avons procédé à un examen rétrospectif de tous les cas de fracture de la mandibule traités à l'Hôpital général de Montréal, de 1998 à 2003. Nous avons revu les dossiers médicaux et les radiogrammes numérisés afin de relever les données démographiques sur les patients et les données factuelles sur les blessures.

RÉSULTATS : L'examen des dossiers a permis de dénombrer 181 patients mais 307 fractures de la mandibule. Cinquante-deux pour cent des fractures ont été enregistrées chez des personnes âgées de 21 à 40 ans; 78 \% d'entre elles étaient des hommes et il y avait une grande diversité ethnique. Soixante pour cent des patients présentaient plusieurs fractures de la mandibule : $29 \%$ touchaient la symphyse et la parasymphyse; $25 \%$, le condyle; et $23 \%$, l'angle mandibulaire. La principale cause des fractures de la mandibule était les agressions; l'alcool et l'usage de drogues illicites étaient mis en cause dans $29 \%$ des cas. Une fracture concomitante de la face accompagnait la fracture de la mandibule chez $30 \%$ des patients, et plus du tiers des personnes concernées avaient subi une autre blessure grave.

CONCLUSIONS : Le présent examen épidémiologique a fait ressortir plusieurs cibles possibles de prévention ainsi que des tendances importantes. D'autres études sur l'efficacité des mesures de prévention permettraient d'établir plus objectivement qu'aujourd'hui leur incidence sur les traumas de la mandibule.

${ }^{1}$ MUHC, McGill University, Montreal Children's Hospital; ${ }^{2}$ Plastic and Reconstructive Surgery, McGill University Health Center, Jewish General Hospital, St Mary's Hospital; ${ }^{3} \mathrm{McGill}$ University Health Center, Montreal General Hospital, Royal Victoria Hospital; ${ }^{4} \mathrm{McGill}$ University Health Center, Montreal Children's Hospital, Royal Victoria Hospital, Montreal, Quebec

Correspondence: Dr Marcin Czerwinski, Plastic Surgery Resident MUHC, McGill University, Montreal Children's Hospital, Plastic Surgery

Office C11, 2300 Tupper Street, Montreal, Quebec H3G 1P3. Telephone 514-412-4488, fax 514-412-4340,

e-mail marcin.czerwinski@mail.mcgill.ca 


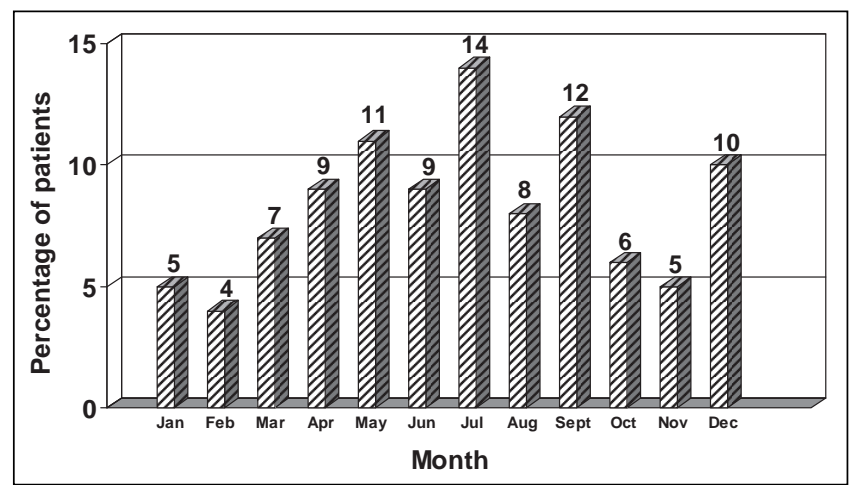

Figure 1) Monthly distribution of mandible fractures

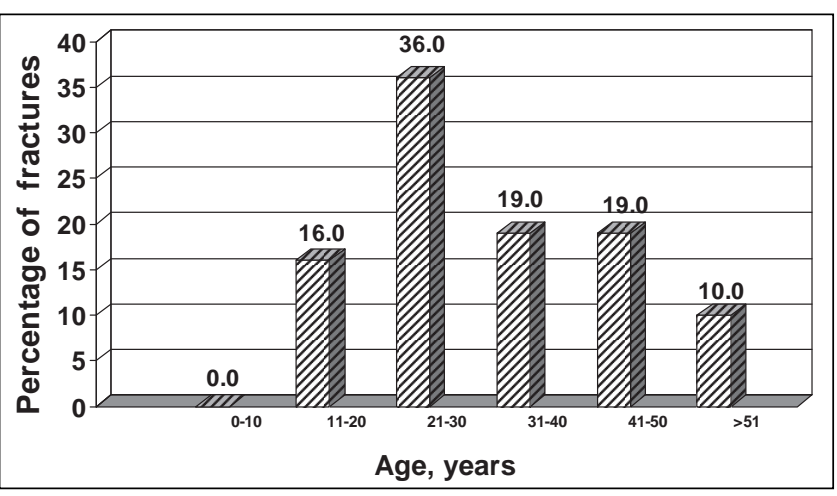

Figure 2) Age distribution of mandible fracture patients
Knowledge of mandibular fracture epidemiology is critical to effective prevention and in the establishment of accurate trauma evaluation protocols. First, patients at high risk of injury, the major causative mechanisms and contributing factors must be identified. Second, the injury patterns associated with these fractures in general and as they occur due to specific mechanisms should be defined. Finally, significant relationships between sample data and population characteristics must be sought.

Several investigators have studied mandibular fracture epidemiology (5-11). However, due to technological, cultural and political influences, it is unreasonable to extrapolate such results among hospital centres and across time. For instance, the implementation of the seat belt law in 1997 in Washington, DC, significantly reduced the contribution of motor vehicle collisions (MVC) to mandibular fractures (11). Societies where alcohol is forbidden have a lower incidence of causative assault (5). Furthermore, the rise in violent crimes in both rural and urban centres $(6,7,11-13)$ has significantly influenced facial trauma patterns.

Only one Canadian study of mandibular fracture epidemiology has been published. Sojot et al (13) retrospectively reviewed mandibular fractures presenting to the Toronto General Hospital Department of Dentistry (Toronto, Ontario) over a 5.5 year period. Their series contribution is limited due to the exclusion of polytrauma victims and of patients treated by other surgical subspecialties. Thus, the applicability of such data to the creation of injury prevention programs and trauma evaluation algorithms is difficult.

The objectives of our study were to identify and contrast the epidemiology of mandibular fractures treated at the Montreal General Hospital (Montreal, Quebec), the main regional level 1 Canadian trauma centre. This is the largest reported Canadian series without a referral bias and inclusive of all mandible fracture patients treated at this centre. Subsequently, we wished to clarify the pathogenesis of epidemiological patterns and to suggest potential targets of preventive efforts.

\section{METHOD}

A retrospective review of all mandibular fracture patients presenting to the Montreal General Hospital between 1998 and 2003 was performed. Patients treated by the Plastic Surgery and the Oral and Maxillofacial Surgery departments, the only two departments responsible for facial trauma care at the hospital, were included.
Medical records (trauma evaluation sheets, consults, operative reports and outpatient clinic notes) and digitized radiographic imaging were used to collect the pertinent information. Data included patient age, sex, alcohol or drug use, injury date and mechanism, location of mandibular and other facial fractures, and presence of other injuries.

Data organization and analysis were performed using Microsoft Excel (Microsoft, USA).

\section{RESULTS}

\section{Fracture incidence and temporal distribution}

In total, 181 patients with 307 mandibular fractures were identified. An equal number of patients were treated by the Plastic Surgery and the Oral and Maxillofacial Surgery departments. Annual percentile distributions were consistent: 1998, 13\%; $1999,21 \%$; 2000, 13\%; 2001, 17\%; 2002, 18\%; and 2003, $18 \%$. Monthly fracture distribution is shown in Figure 1. Over $50 \%$ of the injuries occurred from May to September.

\section{Age, sex and ethnic distribution}

Fifty-two percent of mandibular fractures occurred in individuals 21 to 40 years of age (Figure 2). Seventy-eight percent of patients were male and $22 \%$ were female. Eighty percent of patients in the age 11 to 30 years group were male, whereas this percentage decreased to $60 \%$ within the age 31 to 40 years group. Thirty-eight percent were Caucasian French, with 21\% Caucasian English, 17\% Inuit, 15\% other (European, Hispanic, Asian), 6\% African American heritage and 3\% Arabic.

\section{Fracture location and anatomy}

Symphyseal/parasymphyseal fractures comprised 29\% of all fractures, followed closely by condylar (25\%) and angle fractures $(23 \%)$ (Figure 3$)$. Sixty percent of patients had multiple fractures of the mandible, and $23 \%$ had comminuted injuries. Symphyseal/parasymphyseal fractures were associated with an additional mandibular fracture site $74 \%$ of the time (angle, $44 \%$; condyle, 34\%). Fifty-one percent of fractures in female patients were isolated symphysis/parasymphysis, angle or body; $30 \%$ were combined parasymphyseal/symphyseal and condylar.

\section{Mechanism of injury}

Assault was the most common mechanism of injury, accounting for $41 \%$ of cases, followed by MVCs (26\%) and falls (18\%) (Figure 4). According to the Advanced Trauma Life Support 


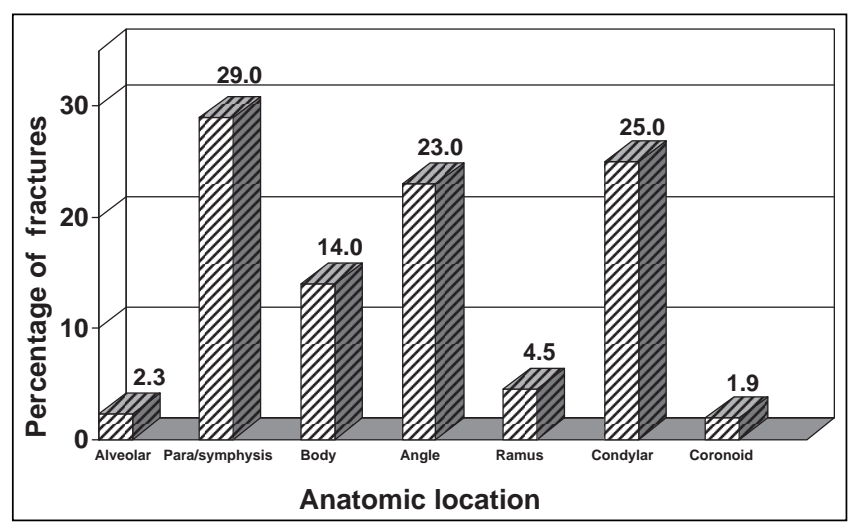

Figure 3) Distribution of mandible fractures by anatomical location

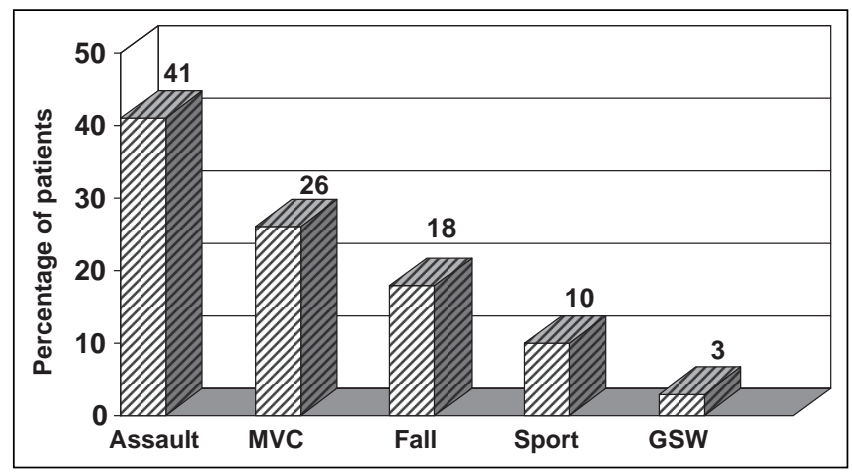

Figure 4) Mechanism of injury of mandible fracture patients. MVC Motor vehicle collision, GSW Gunshot wound

criteria, the mechanism was severe in $45 \%$ of patients. In female patients, $33 \%$ of fractures were due to assault, $33 \%$ were due to MVC and $23 \%$ were due to falls. In male patients, $44 \%$ were due to assault, $25 \%$ were due to MVC and $17 \%$ were due to falls. In the combined 11 to 20 years age group, $55 \%$ of fractures were due to assault and 28\% were due to MVC. In the 21 to 30 years age group, $43 \%$ were due to assault and $24 \%$ were due to MVC. In the 31 to 40 years age group, $35 \%$ were due to MVC and 24\% were due to assault.

\section{Drug or alcohol association}

Twenty-nine percent of mandibular fractures occurred in patients who abuse alcohol or illegal drugs. Thirty-seven percent of assaults and $25 \%$ of MVC were associated with the use of these substances.

\section{Associated facial fractures}

Thirty percent of patients had another associated facial fracture. Of those, $55 \%$ were zygomas, $35 \%$ were nasal bones and 24\% were LeFort fractures (Figure 5). Mandibular fractures caused by a severe mechanism of injury were associated with another facial fracture $59 \%$ of the time. If the mandible was comminuted, another facial fracture was present $48 \%$ of the time.

\section{Associated injuries}

Mandibular fractures were associated with another major injury in over one-third of patients (Figure 6). Of these patients, $62 \%$ had fractures of the spine, pelvis or extremities,

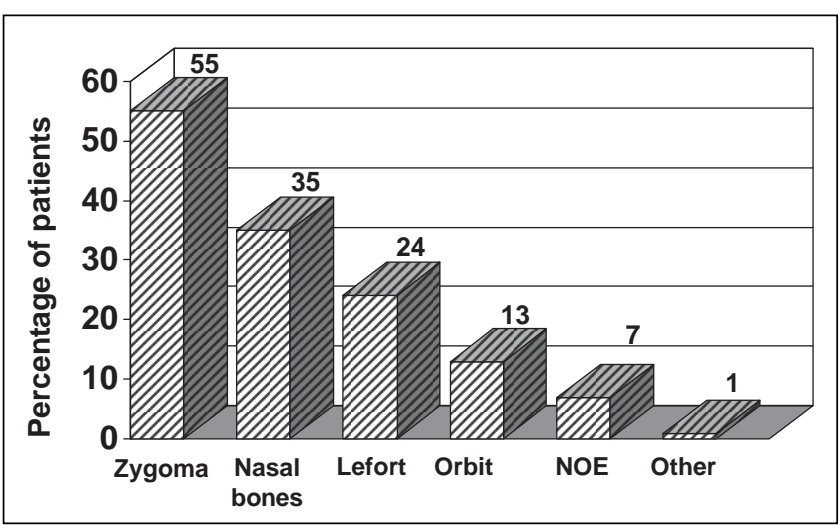

Figure 5) Associated facial fractures identified in mandible fracture patients. NOE Naso-orbital-ethmoidal

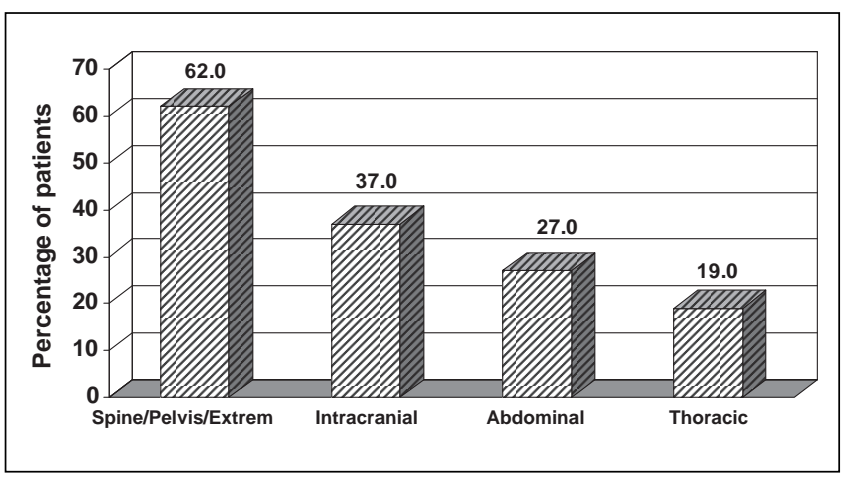

Figure 6) Associated injuries identified in mandible fracture patients. Extrem Extremity

$37 \%$ had intracranial injuries, $27 \%$ had intra-abdominal injuries and 19\% had thoracic injuries. Mandibular fractures due to severe mechanism of injury were associated with another major injury $61 \%$ of the time. Comminution was accompanied by another injury $50 \%$ of the time.

\section{DISCUSSION}

Mandibular fractures are common, can lead to significant early and late complications, and are a potential marker of severe trauma. In addition, these injuries consume a significant portion of the health care budget. Understanding their epidemiology will allow us to more effectively target our preventive efforts and reorganize current trauma evaluation practices. Subsequently, mandibular fracture incidence and sequelae may be diminished. The epidemiological data, however, must accurately represent the target population. We reviewed 181 mandibular fracture patients treated at the Montreal General Hospital, a level 1 Canadian trauma centre that evaluates over 10,000 trauma cases annually. There exist similarities to previous large series; however, several observations can be made from this experience that highlight the unique political, cultural and geographic influences of the region.

Similar to other reports, $78 \%$ of patients in the present sample were male, and over $50 \%$ of injuries were in the 21 to 40 years age group. The percentage of male patients gradually decreased with age, accounting for $80 \%$ of 11 to 30 year olds and $60 \%$ of 31 to 40 year olds. This decrease is likely a reflection of reduced assault rates among older individuals $(55 \%$ of those 11 to 20 years of age, $24 \%$ of those 31 to 40 years of age). In Canada, 
the increased incidence of violence among young adults may be exacerbated by greater ethnic diversity, as accurately demonstrated in this sample. In addition, a lower drinking age in Quebec (compared with the United States and parts of Canada) may be partly responsible for the increased incidence of alcohol use in young assault victims.

Assault was the predominant injury mechanism (41\%), whereas the incidence of MVC (26\%) was higher than in other series (9). Forty-six percent of MVCs were caused by individuals 16 to 30 years of age; $25 \%$ occurred under the influence of alcohol or drugs. An explanation for higher numbers of MVCs in the present sample is possibly twofold: lower legal drinking age and no patient selection bias. Unlike the other Canadian series (13), in which only patients treated by the Dentistry Department were reported, we included all mandibular fracture patients who presented to the hospital. Thus, the predominant etiologies in their review were assault (54\%), fall (22\%) and sport $(12 \%)$, because major polytrauma victims were seen by other departments.

In the present series, over $50 \%$ of fractures occurred during the summer months, unlike the more even distribution seen in large American centres (11). This is likely due to the more severe winter conditions in Canada, which significantly limit prolonged outdoor activities.

Over $50 \%$ of mandibular fractures in female patients were isolated to the symphysis/parasymphysis, body or angle. Thirtythree percent of fractures in female patients were reportedly due to assault and $23 \%$ due to falls. Prior studies $(2,14)$ have shown that direction and magnitude of force vectors resulting from assault tend to produce isolated body or angle fractures, whereas falls or MVCs lead to double symphysis/parasymphysis and condyle fractures. This discordance between the mechanism of injury and anatomical fracture location in female patients may signify potential under-reporting by assaulted women who falsely ascribe their injuries to other causes.

The mechanism of injury was severe in $45 \%$ of patients in the present group. The mandible had multiple fractures in $60 \%$ and comminution present in $23 \%$ of patients. In addition, $30 \%$ of mandibular fractures had an associated facial fracture. Another major injury was present in 34\% of patients, most commonly a skeletal or intracranial injury.

\section{REFERENCES}

1. Brook IM, Wood N. Aetiology and incidence of facial fractures in adults. Int J Oral Surg 1983;12:293-8.

2. Ellis E 3rd, Moos KF, el-Attar A. Ten years of mandibular fractures: An analysis of 2,137 cases. Oral Surg Oral Med Oral Pathol 1985;59:120-9.

3. van Hoof RF, Merkx CA, Stekelenburg EC. The different patterns of fractures of the facial skeleton in four European countries. Int J Oral Surg 1977;6:3-11.

4. Azevedo AB, Trent RB, Ellis A. Population-based analysis of 10,766 hospitalizations for mandibular fractures in California, 1991 to 1993. J Trauma 1998;45:1084-7.

5. Oikarinen K, Schutz P, Thalib L, et al. Differences in the etiology of mandibular fractures in Kuwait, Canada, and Finland. Dental Traumatol 2004;20:241-5.

6. King RE, Scianna JM, Petruzzelli GJ. Mandible fracture patterns: A suburban trauma center experience. Am J Otolaryngol 2004:25:301-7.

7. Wojciechowicz J, Tomaszewski T, Dobiezynska B, Rahnama M. [Mandibular fractures - retrospective study]. Wiad Lek 2004:57:37-43.

8. Ozgenel GY, Bayraktar A, Ozbek S, Akin S, Kahveci R, Ozcan M. [A retrospective analysis of 204 mandibular fractures]. Ulus Travma Acil Cerrahi Derg 2004;10:47-50.
These findings suggest that fractures of the mandible are an indicator of potentially serious injuries, likely because of the high energy required to disrupt this strong structure. Other series (15-21) also report severe associated injuries, with rates as high as $89 \%$, although these series often report on combined facial and not mandible fractures in isolation $(18,22)$. Carlin et al (22) reported associated closed head injuries (40\%), extremity fractures $(33 \%)$, thoracic trauma $(29 \%)$ and traumatic brain injuries $(25 \%)$ in 828 patients sustaining midface and/or mandible fractures. Sixty-seven percent of patients were involved in MVCs and only $11 \%$ of patients had no other significant injury apart from the facial fractures (22). Fischer et al (15) detailed systemic injuries associated with mandible fractures in a series of 148 patients. Life-threatening injuries (skull base fractures, closed head injury, cervical spine fractures, abdominal and chest injuries) were identified in $64.8 \%$ of their patients. When non-life-threatening injuries were included, the incidence of associated systemic injures rose to $99.3 \%$.

\section{CONCLUSIONS}

The present epidemiological review reveals several potential prevention targets as well as significant trends. First, the high incidence of alcohol or drug use in young male patients involved in assault and MVCs should prompt further study of the potential causative influence of the lower legal drinking age in Quebec. Second, the high level of assault in young male patients of diverse ethnic origins may signal the need for greater awareness of cultural diversity through early education programs. Third, potential under-reporting by female assault victims underlines the need for increased awareness of possible abuse and the understanding of particular injury patterns for medical professionals evaluating these patients. If required, the physician should be capable of skillfully addressing this subject with the patient and offer further guidance. Last, mandibular fractures are frequently associated with another major facial or other organ system injury. These potentially life-threatening injuries must be aggressively diagnosed by individuals with appropriate Advanced Trauma Life Support training. Further research into the impact of these preventive measures could more objectively identify their impact on mandibular trauma.

9. Abbas I, Ali K, Mirza YB. Spectrum of mandibular fractures at a tertiary care dental hospital in Lahore. J Ayub Med Coll Abbottabad 2003;15:12-4.

10. David LR, Bisseck M, Defranzo A, Marks M, Molnar J, Argenta LC. Cost-based analysis of the treatment of mandibular fractures in a tertiary care center. J Trauma. 2003;55:514-7.

11. Ogundare BO, Bonnick A, Bayley N. Pattern of mandibular fractures in an urban major trauma center. J Oral Maxillofac Surg 2003;61:713-8.

12. Hung YC, Montazem A, Costello MA. The correlation between mandible fractures and loss of consciousness. J Oral Maxillofac Surg 2004;62:938-42.

13. Sojot AJ, Meisami T, Sandor GK, Clokie CM. The epidemiology of mandibular fractures treated at the Toronto general hospital: A review of 246 cases. J Can Dent Assoc 2001;67:640-4.

14. Busuito MJ, Smith DJ Jr, Robson MC. Mandibular fractures in an urban trauma center. J Trauma 1986;26:826-9.

15. Fischer K, Zhang F, Angel MF, Lineaweaver WC. Injuries associated with mandible fractures sustained in motor vehicle collisions. Plast Reconstr Surg 2001;108:328-31.

16. Kraus JF, Rice TM, Peek-Asa C, McArthur DL. Facial trauma and the risk of intracranial injury in motorcycle riders. Ann Emerg Med 2003;41:18-26. 
17. Slupchynskyj OS, Berkower AS, Byrne DW, Cayten CG. Association of skull base and facial fractures. Laryngoscope 1992;102:1247-50.

18. Haug RH, Savage JD, Likavec MJ, Conforti PJ. A review of 100 closed head injuries associated with facial fractures. J Oral Maxillofac Surg 1992;50:218-22.

19. Andrew C, Gallucci JG, Brown AS, Barot LR. Is routine cervical spine radiographic evaluation indicated in patients with mandibular fractures? Am Surg 1992;58:369-72.

20. Bayles SW, Abramson PJ, McMahon SJ, Reichman OS. Mandibular fracture and associated cervical spine fracture, a rare and predictable injury. Protocol for cervical spine evaluation and review of 1382 cases. Arch Otolaryngol Head Neck Surg 1997;123:1304-7.

21. Ardekian L, Gaspar R, Peled M, Manor R, Laufer D. Incidence and type of cervical spine injuries associated with mandibular fractures. J Craniomaxillofac Trauma 1997;3:18-21.

22. Carlin CB, Ruff G, Mansfeld CP, Clinton MS. Facial fractures and related injuries: A ten-year retrospective analysis.

J Craniomaxillofac Trauma 1998;4:44-8. 